\title{
DEPARTMENT OF PUBLIC HEALTH NURSING
}

IN CHARGE: OF

EDNA I. FOLFY, R.N.

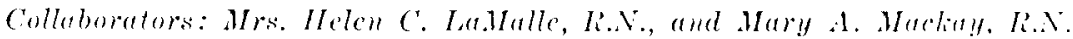

\section{A PlloRIIIC:F TO 'THE SHRINES}

August 15, 1919. To-day is a national festa, the feast of the Assumption, and no one is working, not even the museums, as we learned to our sorrow when we started out to explone the doisters of Santa croce, where we hat heard there was a statute of Florence Nightingale. The guard looked at us impersonally, removed his speetacles and uttered one word, "chinsa," (closed). As we looked blank he grew a little more loqualcious: "Oggi festa apreta domari." (Today is a holy day; open to-morrow.) In halting Italian we explained that to-morrow would see us in Rome and that we had come to visit the shrine of the celebrated "domma Inglese." Florence Nightingale. He may have suspected that we were willing to pay for the privilege, but we think that he saw my Red Cross pin. However they may recard our statesmen, the Italians love the croce Rossa Ameriduan, and the newpaper was discarded, the spectacles pocketed, and the door opened into the famous cloister of old Sinta croce or the Franciscan chureh of the Holy Cross.

The memorial is in the western wall, to the right as one enters, just a few rods from the gate. The rather small statue of Carrara marble is set in a niche in the wall, and is surounded by an oval frame of gray composition, carved in rather high relief. The pose is that of a person caught in passing, the hear inclined down a bit as if a patient were just beneath, the old Roman lamp lifted to prevent even its faint rays from disturbing his rest. The lines of the drapery suggest a vestal Virgin or a night watcher, momentarily arrested while making her rounds.

The gentle face, the really beautiful hands, the restrained but graceful draperies, all combine to make a slender, lovely figure, appealing alike in its simplicity and strength. The face is not a portrait, the draperies are certainly not the ugrly mid-Victorian-period dress in which she is always depicted, but the whole effect of the pose, the lamp and the draperies expresses the spirit of the patron saint of good nursing as the world pictures her and as she must have appeared to the pain-racked soldiers of the Crimea. On the small flat pedestal are two Latin words, Horam Mescitis (In the hour of necessity). Set 


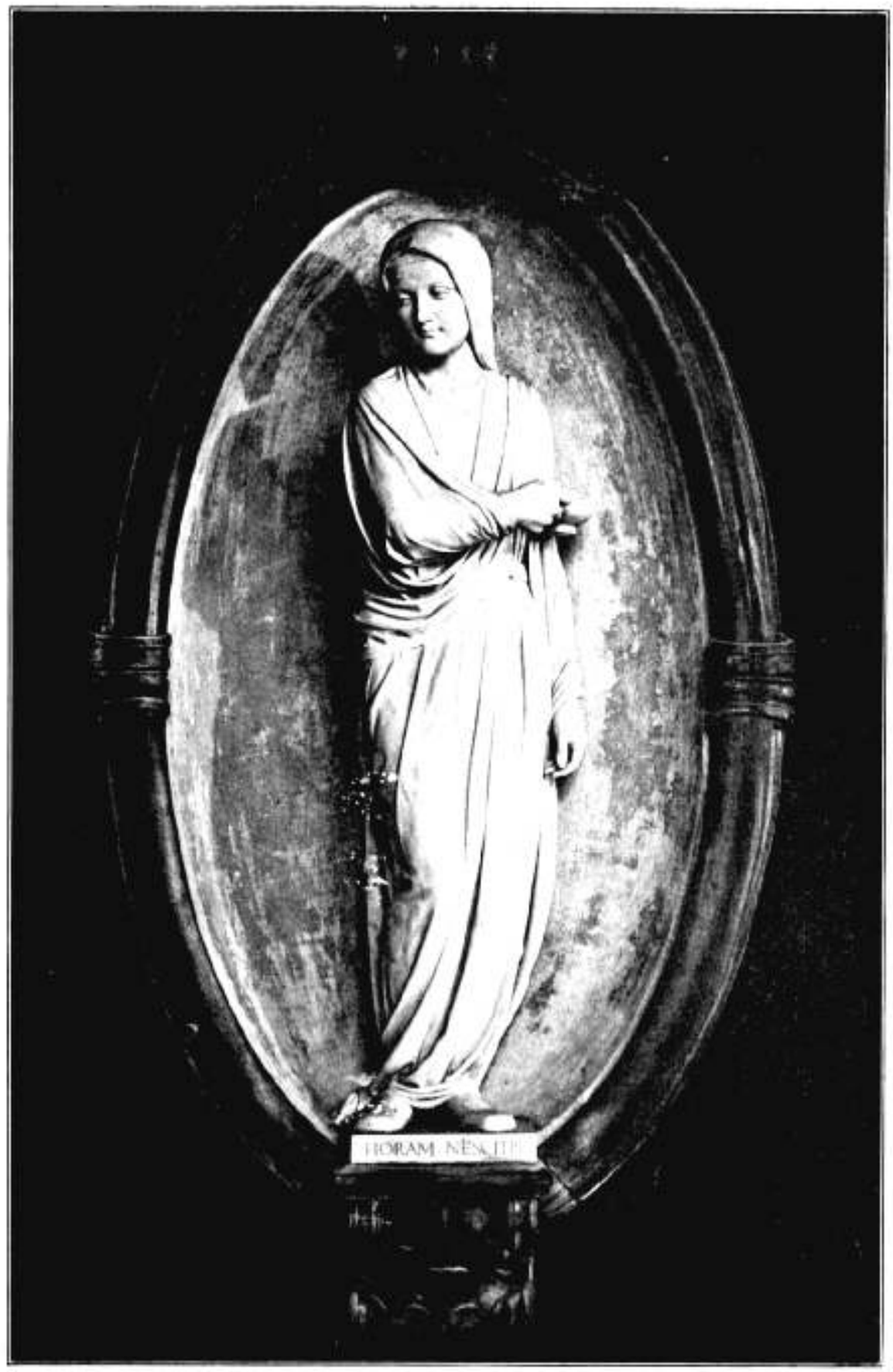

Statue of Florence Nightingale in the cloister of Santa Croce. 


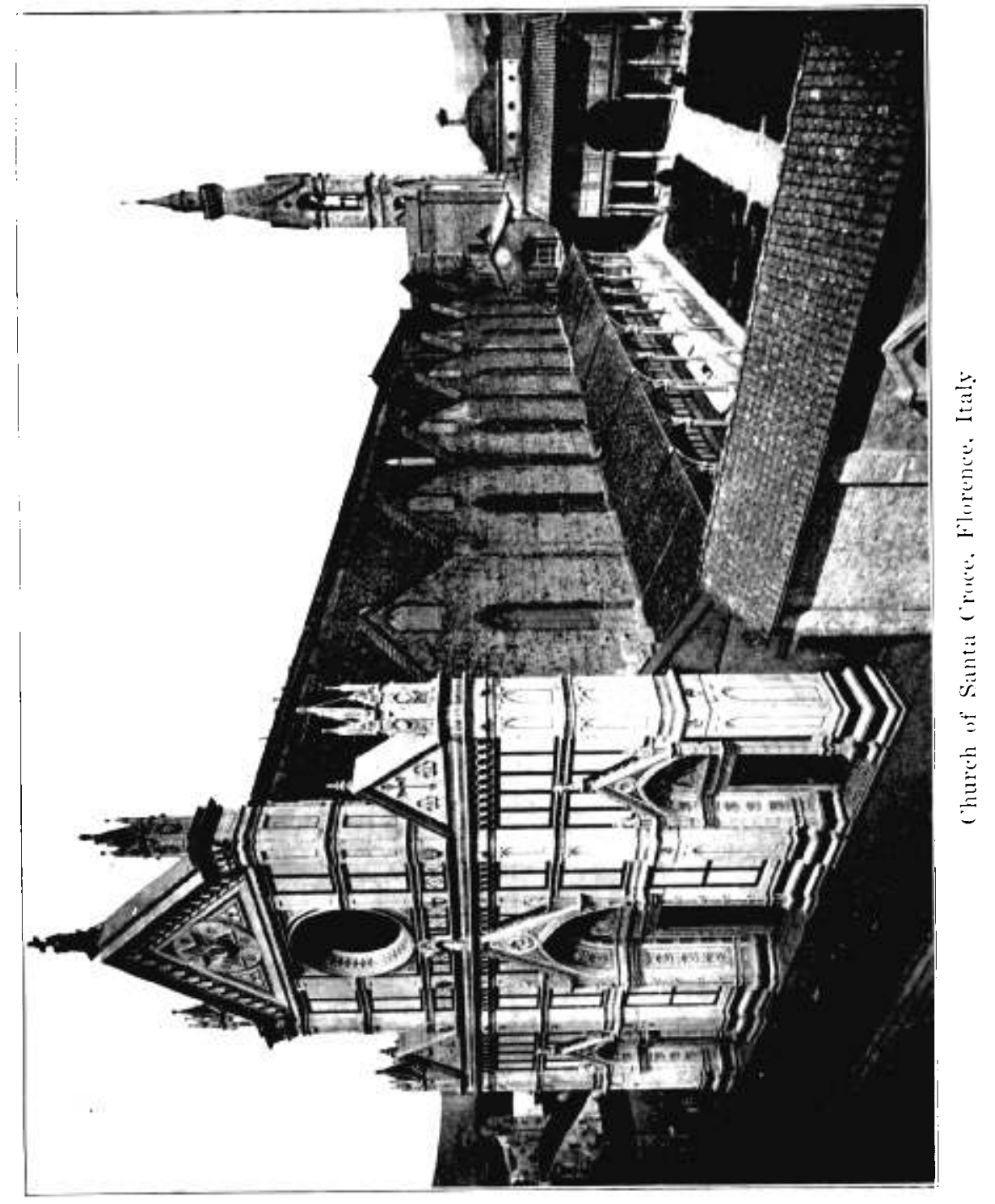




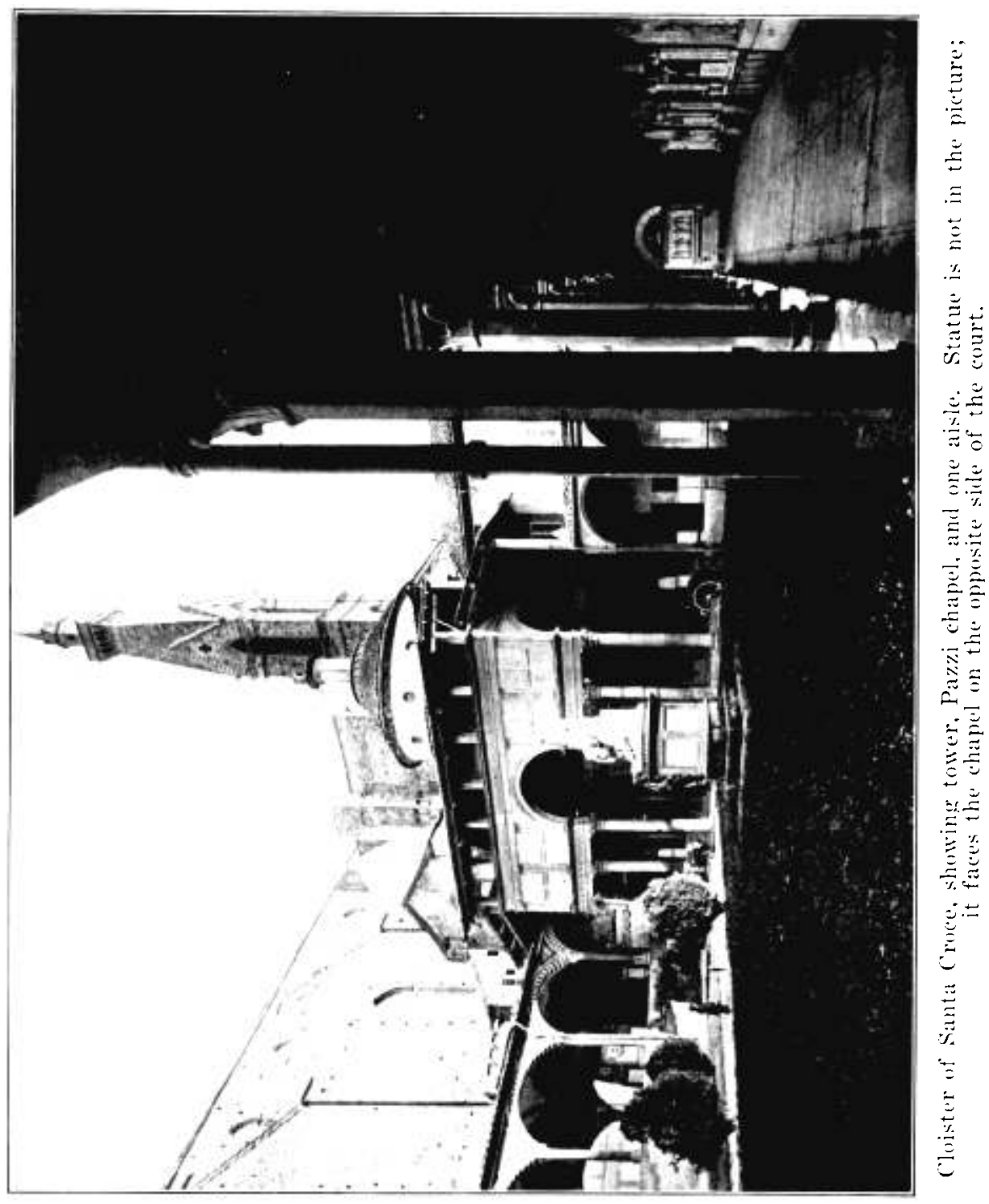




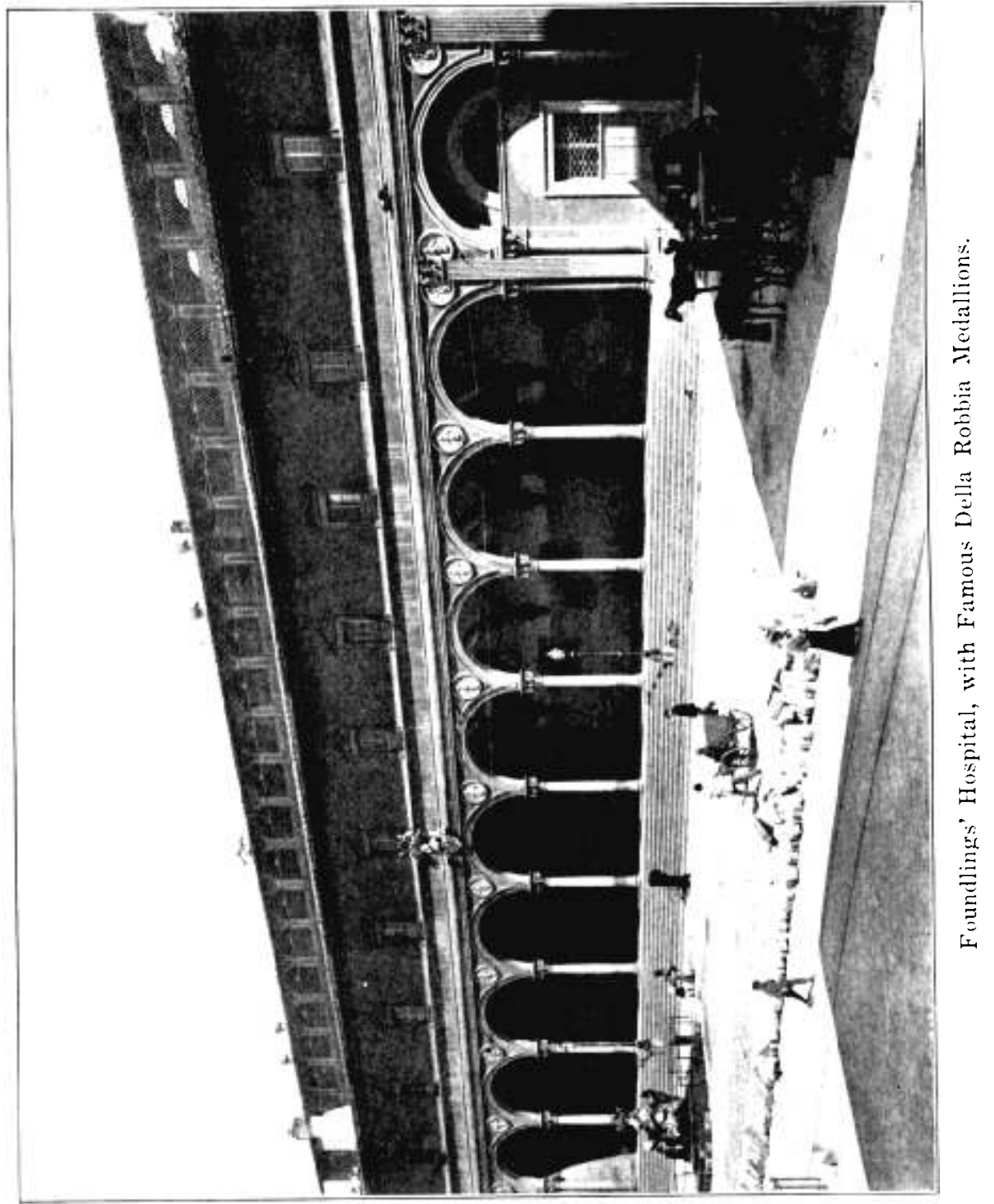




\section{I) prartment of Public Health Nursing}

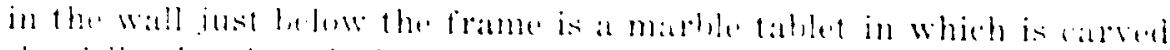
the fullumin! inseriptinn:

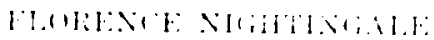

MHer.x.

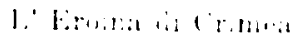

$11119+8$

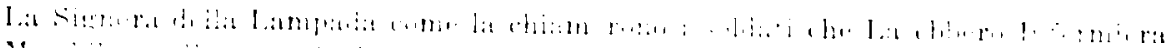

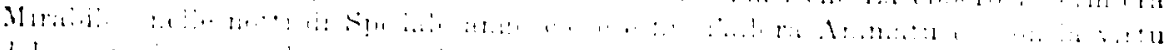

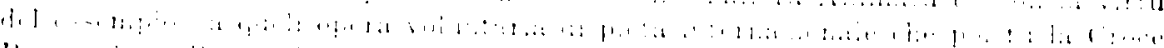

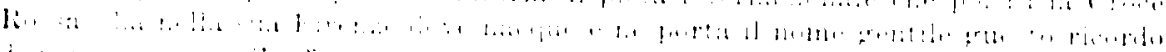
, $\quad \ldots, \cdots, \ldots, \ldots, \ldots$

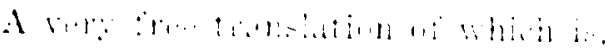

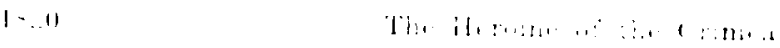

$\vdots \because: 11$

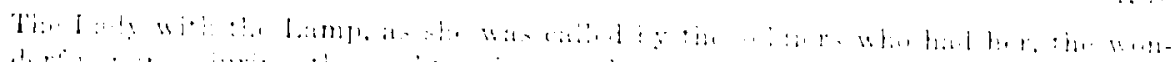

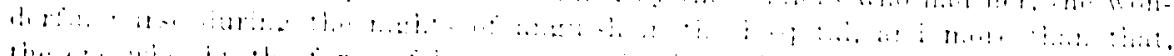

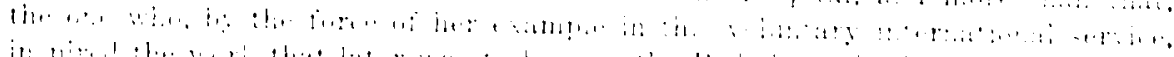

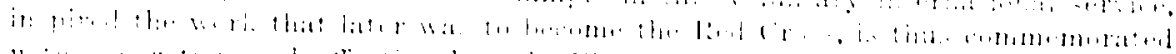

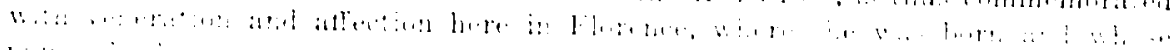

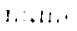

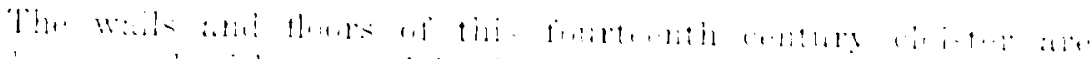

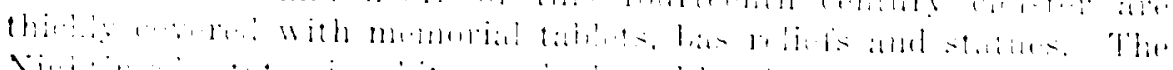

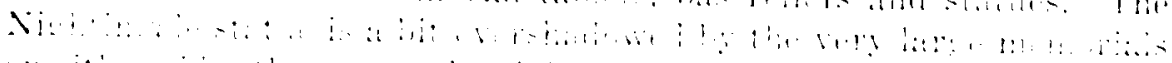

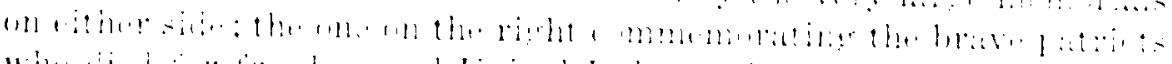

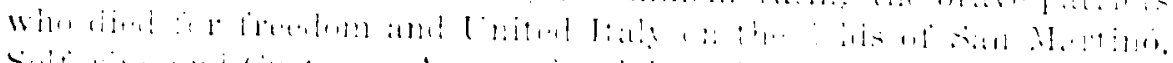

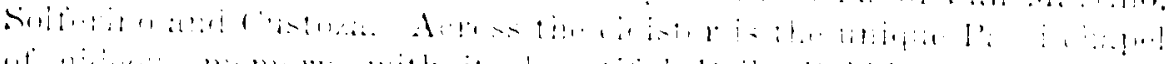

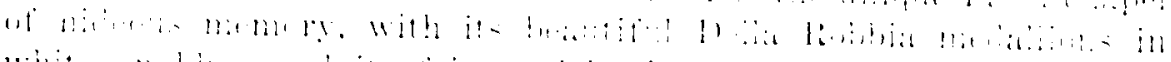

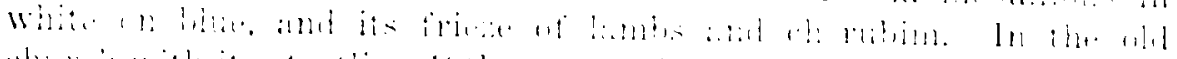

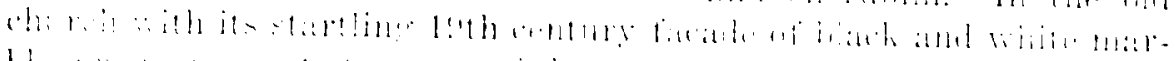
bl. a

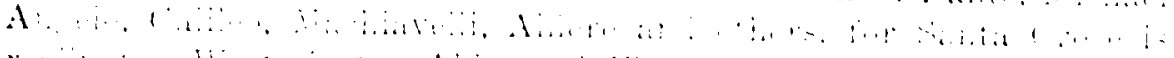

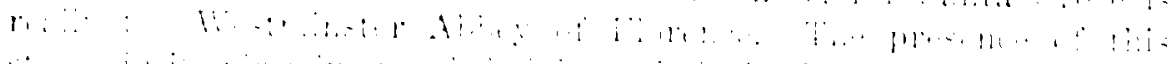

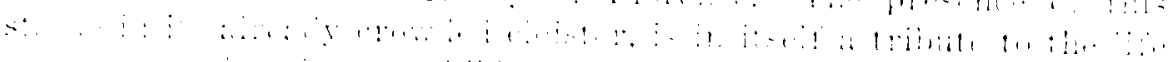

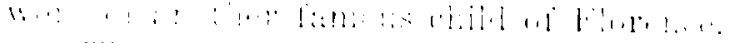

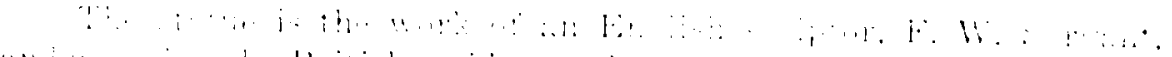

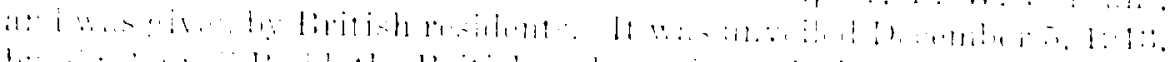

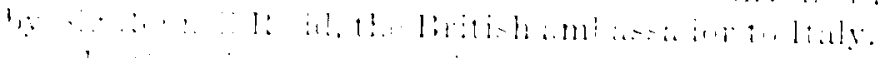

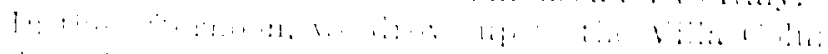

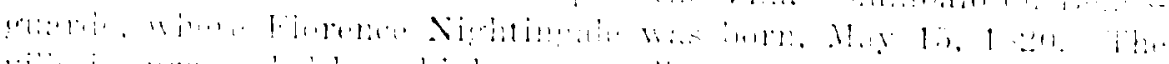

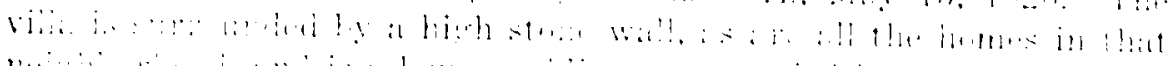

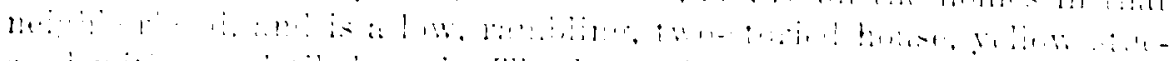

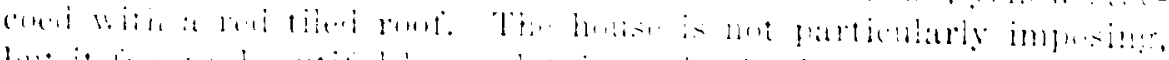

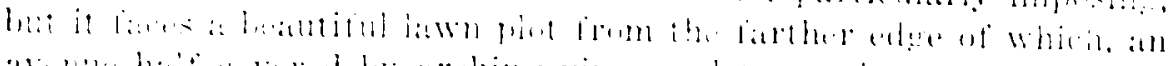

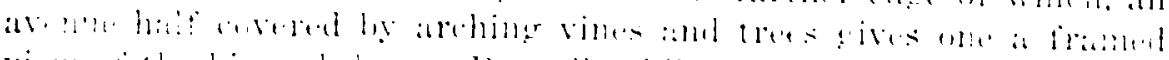

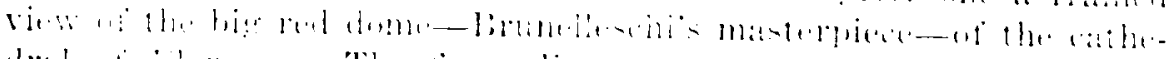

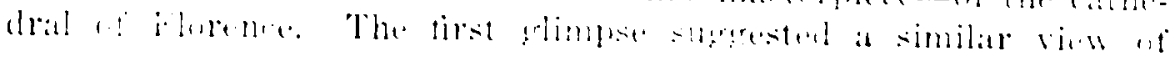


Michael Angelo's great dome of St. Peter's which one gets, framed in an : wemue of cypress trees, from the key-hole of the gateway into the Knirhts of Malta's monastery on the Arentine. The concierge of Villa (olumbaio was nore hospitable than the old knights, however, for he did not demand a pass--and he refused a tip. As we walked down the avenue botween its stately rows of evergreen trees, we discovered that it ended in a termare from which one gets a most wonderful view of Florence and the Appennines beyond, one of the most aplualingr. beautiful panoramas in Italy.

Iany templiner little shatly paths led off from the aremue; in fart. the estate needed hours for its enjoyment and exploration. It was in Corman hamls for beats before the war when it was, of course, onnfiscated and later was used as a hospital for convalesent soldiels. Although it was a fairly lene lrive after we left the Porta liomana

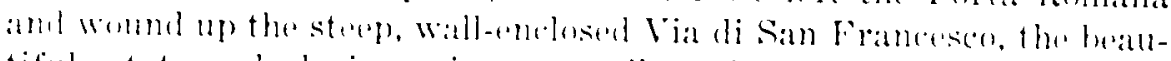
tiful estate and groriols view, as well as the sentimental interest of

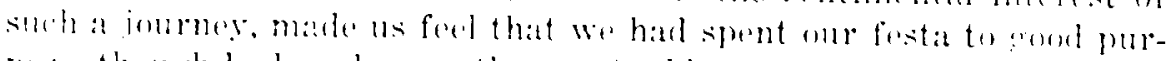

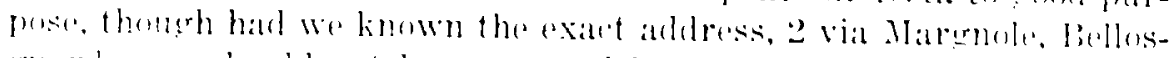
gratribe we shoukd not have courted heat prostration se assiblumsly.

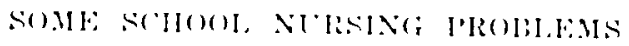

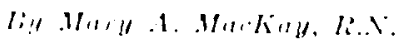

Many of the rural sehewl muses ale weighing and measuring the sehomel children in combertion with the ir physical examinations. Fome

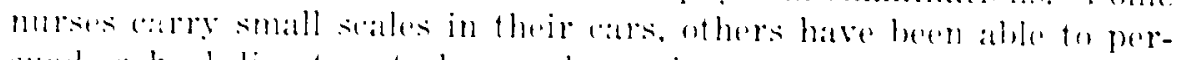
sllate schend directors to huy scales and some nurses let the childeren weigh themselves oneer a month at the nearest grencers. The attratetive

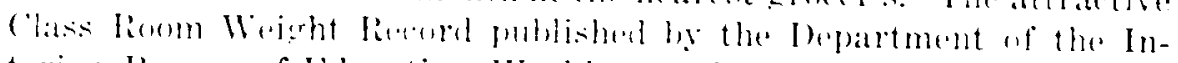

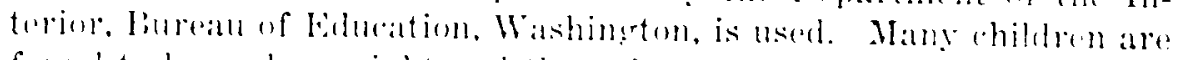

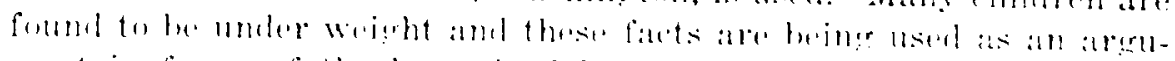

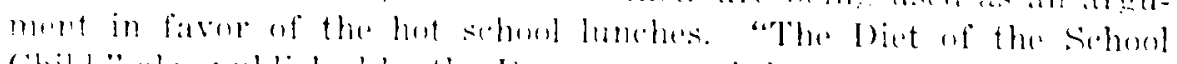

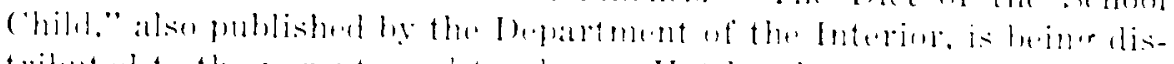

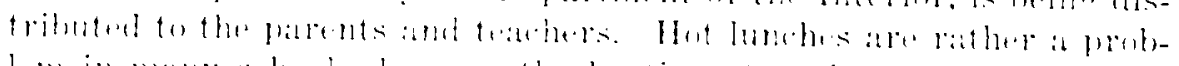

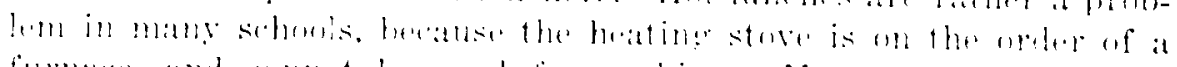

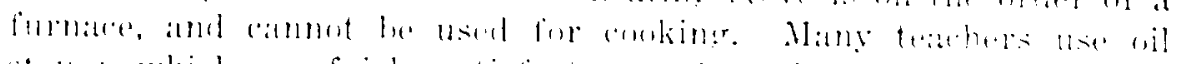
stuses. whith are fably sattisfatory some hatre suth iently large

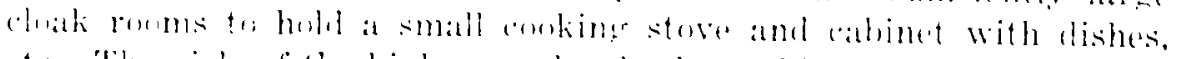

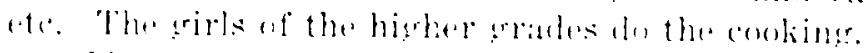

If any of the reatlers of this llepartmont heve solved this problem, will they not write theil solutions and, if possible, semel photogratuhs: 